\title{
Impregnation of kraft paper support with polylactic acid multilayers
}

\author{
Sandra Rivero ${ }^{1 *}$, Javier Lecot ${ }^{1}$, Adriana Pinotti $^{2}$ \\ ${ }^{I}$ Centro de Investigación y Desarrollo en Criotecnología de Alimentos (CIDCA), (CCT La Plata) CONICET, \\ Facultad de Ciencias Exactas, UNLP, 47 y 116, La Plata (1900), Argentina \\ ${ }^{2}$ Facultad de Ingeniería, UNLP, 47 y 116, La Plata (1900), Argentina \\ *Corresponding author, Tel./Fax: (+54) 2214254853; E-mail: sandra_gmr@yahoo.com
}

Received: 14 September 2016, Revised: 05 December 2016 and Accepted: 12 December 2016

DOI: $10.5185 /$ amlett.2017.7107

www.vbripress.com/aml

\begin{abstract}
PLA coating on Kraft paper is very promising systems for food packaging, and has potential environmental advantages over conventional synthetic paper coatings. This work was focused on: (i) analyzing the physicochemical, thermal and microstructural properties of PLA films; (ii) developing and studying multilayer systems obtained by impregnation of Kraft paper with different layers of PLA solution; (iii) evaluating the influence of PLA layers on the support cellulosic properties. The PLA coating improves packaging material performance and hence the functional properties of Kraft paper. The impregnation of hygroscopic materials as the Kraft paper with PLA was an alternative interesting to obtain more hydrophobic matrices. The assembled materials attained were heat-sealed. Furthermore, the use of PLA adds to potential food applications, a renewable resource value obtained from sources agricultural. The design of this multilayer support also allows its extension to other media such as paperboard. Moreover, the addition of 4 or 5 layers favourably modified the assembled system properties. Increasing even further the number of PLA layers, system properties hardly underwent a significant improvement. Consequently, the selection of the number of PLA layers would be a response to a relationship of commitment between the increase in the cost and the enhancement of the properties. Copyright $(\mathcal{C} 2017$ VBRI Press.
\end{abstract}

Keywords: Coating, PLA, mechanical properties, water uptake, water barrier properties.

\section{Introduction}

In the packaging industry, cellulose fiber-based matrices have been widely used replacing synthetic materials because they are considered eco-friendly materials. Kraft paper has a porous cellulose structure based on microfibrils, which are composed of long-chain cellulose packaged and organized into crystalline and amorphous domains. The hydrophilic nature of cellulose, because of the $\mathrm{OH}$ sites in the monomeric unit of cellulose and its fiber network porosity, limits the water vapor barrier properties of paper [1].

Naturally, renewable biopolymers have been the focus of much research in recent years such as starch, chitosan, corn-zein and cellulose derivatives. They have been used as common coating materials in order to improve the barrier and mechanical properties [1,2]. However, these biopolymers are hydrophilic in nature; thus, to improve water resistance properties of paper packaging, recent research has focused on coatings based on hydrophobic biopolymers. Poly(lactic acid) (PLA) constitutes the most researched biodegradable aliphatic polyester which has acquired increasing attention in the last few years as a food packaging material. In addition to its biodegradability, PLA is used for a wide range of applications, due to its renewability and excellent physical

Copyright (C) 2017 VBRI Press and mechanical properties, good processability and low cost [3]. PLA is considered the most promising biopolymer which can be produced by fermentation of carbohydrate feedstock such as sugars, molasses, sugar beet juice, sulphite liquors, or agricultural waste products [4].

Kraft paper is used as a material for the manufacture of low cost packaging, which needs good mechanical properties. The hydrophilic properties and the water vapor barrier of the Kraft paper are not suitable for foodstuff storage in environments with high relative humidity, since this material is hygroscopic and porous, hence the moisture migration occurs by diffusion of water vapor through the void spaces as well as in condensed form through the fiber cell walls. This fact can decrease or even deteriorate the mechanical strength of paperboard $[\mathbf{1 ,} \mathbf{5}$, 6]. Alternatives to enhance the materials properties result from the combination of two or more layers of single material for obtaining bilayer or multilayer systems [7]. Multilayer technology can be carried out by impregnating or coating a support with the polymer solution, or by assembling multilayer thin films by sequential deposition layer-by-layer [8]. One of the key issues to develop multilayer arrays is to control the interfaces between materials. Typically, these structures can combine different polymers in which each layer has a specific 
function where the outer layer provides structural properties and acts as a barrier to water vapor and gases. This methodology would allow designing materials with excellent mechanical properties that act as passive or active barriers for food applications. Table 1 shows different biopolymers used to modify the properties of cellulosic support by a coating process, reported according to the studies of different authors.

Table 1. Applications of biopolymers for paper packaging materials illustrated in reviews.

\begin{tabular}{|c|c|c|}
\hline $\begin{array}{c}\text { Polymers } \\
\text { used for } \\
\text { paper } \\
\text { packaging } \\
\text { materials } \\
\end{array}$ & Technique & Reference \\
\hline Chitosan & Coating of paper & Bordenave et al. \\
\hline Chitosan- & with single layer & {$[9]$} \\
\hline $\begin{array}{l}\text { caseinate } \\
\text { bilayer }\end{array}$ & $\begin{array}{l}\text { Coating method: } \\
\text { single-layer and by- }\end{array}$ & $\begin{array}{l}\text { Khwaldia et al. } \\
\text { [10] }\end{array}$ \\
\hline Whey protein & layer & Han and \\
\hline isolate & Coating of paper & Krochta, [11] \\
\hline Starch acetate & with single layer & Matsui et al. \\
\hline Poly-3- & $\begin{array}{l}\text { Coating of Kraft } \\
\text { paper with single }\end{array}$ & $\begin{array}{l}\text { [12]; Larotonda } \\
\text { et al. }[\mathbf{6}, \mathbf{1 3}]\end{array}$ \\
\hline hydroxy & layer & Shawaphun et \\
\hline $\begin{array}{l}\text { butyrate and } \\
\text { polylactic } \\
\text { acid }\end{array}$ & $\begin{array}{l}\text { Coating of paper } \\
\text { with single layer } \\
\text { after the exposition }\end{array}$ & al. $[14]$ \\
\hline Polylactic & of different times & \\
\hline acid & $\begin{array}{l}\text { Single layer coating } \\
\text { of paperboard with } \\
\text { PLA solutions of } \\
\text { different } \\
\text { concentrations }\end{array}$ & Rhim et al. [15] \\
\hline $\begin{array}{l}\text { Alginate and } \\
\text { soy protein }\end{array}$ & $\begin{array}{l}\text { Coating } \\
\text { paperboard } \\
\text { single layer }\end{array}$ & Rhim et al. [16] \\
\hline
\end{tabular}

According to Rhim and Kim [17], heat-sealing property of coating materials is needed for the manufacture of packaging. Consequently, the new type of coating material must have not only hydrophobic and good film-forming properties but also heat- sealing properties. In order to perform Kraft paper materials with good moisture proof and waterproof properties, a barrier layer can be formed by changing the wettability of the Kraft paper surface with sizing agents or coating with hydrophobic materials. In this context, this work was focused on: (i) analyzing the physicochemical, thermal and microstructural properties of PLA films; (ii) developing and studying multilayer systems obtained by impregnation of Kraft paper with different layers of PLA solution; (iii) evaluating the influence of PLA layers on the support cellulosic properties.

\section{Experimental}

\section{PLA film preparation}

Polylactic acid (PLA) grade 4043D provided by Natureworks ${ }^{\circledR}$ was used. PLA filmogenic solutions $4 \%$ $(\mathrm{w} / \mathrm{v})$ were prepared by solubilization in chloroform by stirring for $3 \mathrm{~h}$. The concentration used in this study was based on the solubility of PLA and spreadability of the solution.

The PLA films were obtained by casting of the filmogenic solution into teflon plates, which were left under a chemical laboratory hood. In order to ensure removal of the solvent from the matrix, the samples were stored in a vacuum oven at $60^{\circ} \mathrm{C}$ for $24 \mathrm{~h}$.

\section{Preparation of multilayer systems}

The Kraft paper $\left(132 \mathrm{~g} \mathrm{~m}^{-2}\right)$ used in the experiments was purchased from a local market of La Plata, Argentina. The specimens were obtained by coating a Kraft paper support by means of a PLA solution. The samples were built up on a layer-by-layer basis. Therefore, Kraft paper was impregnated with successive layers (L) of PLA (between 1 and 7) and kept up to achieve the embedding of the PLA solution on the support. Before adding the following layer, between two successive layers, the coated samples were dried under the laboratory hood at room temperature $\left(20^{\circ} \mathrm{C}\right)$ for $24 \mathrm{~h}$.

The resultant film was peeled intact from the casting surface. Prior to analysis, the films were conditioned in a controlled room at $20^{\circ} \mathrm{C}$ and $50 \%$ relative humidity $(\mathrm{RH})$. From here onwards, Kraft paper coated with layers of PLA will be called $1 \mathrm{~L}, 2 \mathrm{~L} \ldots$ with $\mathrm{L}=7$.

\section{Characterization of polylactic acid films}

\section{Modulated differential scanning calorimetry (MDSC)}

MDSC studies of PLA films were performed over a temperature range between $-100{ }^{\circ} \mathrm{C}$ and $350^{\circ} \mathrm{C}$ by using a DSC model Q100 controlled by a TA 5000 module (TA Instruments, New Castle, Delaware, USA), with a quench-cooling accessory, under a $\mathrm{N}_{2}$ atmosphere $(20 \mathrm{ml}$ $\min ^{-1}$ ) and modulated capability. A standard heating ramp

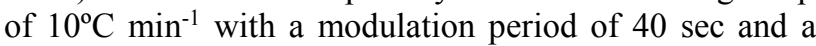
modulation temperature amplitude of $0.5^{\circ} \mathrm{C}$ were chosen. The samples were weighed and prepared as described in previous work [18].

PLA film was exposed to a heat-cool cycle. The cycle program consisted of a first heating stage from -80 to $200^{\circ} \mathrm{C}$ at a heating rate of $10^{\circ} \mathrm{C} \mathrm{min}^{-1}$, followed by a cooling process up to $-80^{\circ} \mathrm{C}$ and subsequent heating up to $200^{\circ} \mathrm{C}$ at $10^{\circ} \mathrm{C} \mathrm{min}^{-1}$. The glass transition temperature $\left(\mathrm{T}_{\mathrm{g}}\right)$ was taken at the midpoint of reversible heat flow curve. The melting temperature $\left(\mathrm{T}_{\mathrm{m}}\right)$ and cold crystallization temperature $\left(\mathrm{T}_{\mathrm{c}}\right)$ were obtained from the first heating. All results were the average of two replicates.

The total, reversing and non-reversing signals were determined. The analysis of the thermograms was performed by using the Universal Analysis V1.7F software (TA Instruments).

\section{Dynamic mechanical analysis (DMA)}

DMA assays of PLA films were conducted in a dynamicmechanical thermal equipment by using a tension clamp with a liquid $\mathrm{N}_{2}$ cooling system as described in a 
preliminary study [18]. Multi-frequency sweeps (5, 10 and $15 \mathrm{~Hz})$ at a fixed amplitude $(15 \mu \mathrm{m})$ from -90 to $200^{\circ} \mathrm{C}$ at $5^{\circ} \mathrm{C} \mathrm{min}^{-1}$ were carried out, with an isotherm of $15 \mathrm{~min}$ at $-90^{\circ} \mathrm{C}$. Each informed value corresponded at least to two determinations.

\section{$X$-Ray diffraction}

PLA films were analyzed by X-ray diffraction in an X'Pert Pro P Analytical Model PW 3040/60 (Almelo, The Netherlands). The $\mathrm{CuK} \alpha$ radiation (1.542 $\AA$ ), operated at room temperature, was generated at $40 \mathrm{kV}$ and $30 \mathrm{~mA}$, and the relative intensity was recorded in the scattering range of $(2 \theta) 3-60^{\circ}$ with a step size of $0.02^{\circ}$.

The area of the crystalline peak diffraction (AP) relative to the total area of the diffractogram (AT) was determined and the crystallinity degree (CD) was calculated as follows,

$$
C D={ }_{A T}^{A P} \times 100
$$

A similar procedure was described by Villarruel et al. [19].

\section{FT-IR spectroscopy}

ATR/FTIR spectra of the samples were recorded by a Nicolet, iS10 Thermo Scientific (Madison, USA) in the wavenumber range $4000-400 \mathrm{~cm}^{-1}$ by accumulation of 64 scans at $4 \mathrm{~cm}-1$ resolution. Samples were placed onto the diamond ATR crystal (Smart iTX accessory) for the Nicolet $^{\mathrm{TM}}$ iS $^{\mathrm{TM}} 10$ (Thermo Scientific ${ }^{\mathrm{TM}}$, Madison, USA). Data were analyzed by using the software Omnic 8 (Thermo Scientific, Madison, USA).

\section{Characterization of impregnated kraft paper}

Coated Kraft paper color was determined by using a Minolta colorimeter CR 300 Series (Osaka, Japan) calibrated with a standard $(\mathrm{Y}=93.2, \mathrm{x}=0.3133$, $\mathrm{y}=0.3192$ ). The CIELab scale was used, lightness ( $\left.\mathrm{L}^{*}\right)$ and chromaticity parameters $\mathrm{a}^{*}$ (red-green) and $\mathrm{b}^{*}$ (yellow-blue) were measured. Assays were performed placing the film samples over the Kraft paper. Samples were analyzed in triplicates, recording six measurements for each sample.

Color differences $(\Delta \mathrm{E})$ were also calculated as was described by Rivero et al. [7] by means of the following equation:

where,

$$
\begin{aligned}
\Delta L^{*} & =L^{*}-L_{0}^{*} \\
\Delta a^{*} & =a^{*}-a_{0}^{*} \\
\Delta b^{*} & =b^{*}-b_{0}^{*}
\end{aligned}
$$

being: $L_{0}^{*}, a_{0}^{*}, b_{0}^{*}$, the color parameter values of the Kraft paper and $\mathrm{L}^{*}, \mathrm{a}^{*}, \mathrm{~b}^{*}$, the color parameter values of the sample.

\section{Thickness, coating weight, and grammage}

Film thickness was determined by using a coating thickness gauge Check Line DCN-900 (New York, USA) for non-conductive materials on non-ferrous substrates. The informed values correspond to the average of at least ten measurements at different positions for each specimen.

The grammage weight $\left(\mathrm{g} \mathrm{m}^{-2}\right)$ of coated Kraft paper was determined gravimetrically by using a precision balance with an accuracy of $0.1 \mathrm{mg}$. Coating weights $\left(\mathrm{g} \mathrm{m}^{-2}\right)$ were determined by subtracting the weight of the uncoated Kraft paper from the weight of the coated sample.

\section{Water uptake assays}

Water uptake was determined by immersion of coated and uncoated samples previously weighted specimens in $100 \mathrm{ml}$ distilled water. After different times of hydration, PLA coated Kraft paper were recovered and dried with filter paper to remove the excess of surface water and weighted again (weight of swollen sample). The water uptake of the films was calculated as follows,

$$
\% \text { Water uptake }=\left[\frac{\left(\mathrm{W}_{\mathrm{t}}-W_{i}\right)}{\mathrm{W}_{\mathrm{i}}}\right] \times 100
$$

where, Wt is the weight of the swollen sample at time $t$ and $\mathrm{Wi}$ is the weight of the dried sample. Samples were analyzed at least in triplicate.

\section{Water vapor transfer rate (WVTR)}

Assays were performed using a modified ASTM method E96 [20] as described in a previous work by means of a specially designed cell with silica-gel [7]. Water vapor transmission rate (WVTR, $\mathrm{g} \mathrm{s}^{-1} \mathrm{~m}^{-2}$ ) was calculated from the slope of the straight line by linear regression $\left(r^{2}>0.99\right)$. Permeance $\left(\mathrm{g} \mathrm{Pa}^{-1} \mathrm{~s}^{-1} \mathrm{~m}^{-2}\right)$ was calculated as the WVTR divided by the partial vapor pressure gradient across the film (1753.55 $\mathrm{Pa}$ at $\left.20^{\circ} \mathrm{C}\right)$.

\section{Mechanical properties}

\section{Puncture test}

Puncture tests were performed in a texturometer TAXT2 $\mathrm{i}$, Stable Micro Systems (England). A cylindrical probe of $2 \mathrm{~mm}$ in diameter at a constant rate of $1 \mathrm{~mm} \mathrm{~s}^{-1}$ was used. Tests were performed on a probe of $4 \times 4 \mathrm{~cm}$ made up of both, the Kraft paper and a first PLA coating, and also after adding a new layer up to 7. Each informed value corresponded to at least ten determinations. Curves of force $(\mathrm{N})$ as a function of deformation $(\mathrm{mm})$ were automatically recorded by the Texture Expert Exceed software. According to Siracusa et al. [21] the underlying area to the curve expressed as $\mathrm{J}$ represents the material tenacity. Each informed value corresponded at least to ten determinations.

\section{Heat-sealing resistance}

The heat-seals were produced using an impulse-wire thermosealer Dasa FS200 (Argentina). Irrespective of the number of PLA layers, the optimum time that allowed 
obtaining the best zip quality was $3.17 \pm 0.15 \mathrm{sec}$. Heatsealing mechanical resistance, which is an indicator of zipping quality, was evaluated in the texturometer previously mentioned, equipped with a tension grip system A/TG using probes of $36 \mathrm{~mm}$ long and $12 \mathrm{~mm}$ wide. The assays were performed after the heat seal was cooled down and became stable. For each specimen, ten probes were used. Mechanical patterns were registered and failure modes were determined according to ASTM standard method F88-00 [22]. The knowledge of the failure mode of a heat-sealed material is critical since it conditions the packaging performance and describes how the two sealed surfaces are separated during the heat sealing resistance assays [23]. Different failure modes (adhesive, cohesive, delaminated, fracture of film at seal edge, fracture of film remote from seal, stretching and adhesive plus stretching) are described by ASTM F88-00 standard method [22]. The necessary energy to cause the failure was also calculated as the area under the curve and expressed in $\mathrm{J}$ [23]. The resistance of heat-seal was determined by measuring the peak force required to pull apart the pieces of the sample strip that have been sealed together, on the same texturometer mentioned in the tensile test section. These parameters allow evaluating the mechanical strength of the seal, assuring proper bonding to maintain package integrity.

\section{Film tear-propagation resistance}

Tear-propagation resistance of the films was determined by using the texturometer TA.XT2i-Stable Micro Systems with a tension grip system A/TG according to the standard testing method ASTM D1938-02 [24] with some modifications [7]. Film probes of $75 \mathrm{~mm}$ length and 25 $\mathrm{mm}$ width were used; a minimum of eight probes were analyzed from coated and uncoated Kraft paper. In each probe, a tear was performed in the middle of the probe width cutting it up to $2 / 3$ of its length. The initial force to continue the propagation of the tear $(\mathrm{N})$ and the extension at maximum force $(\mathrm{mm})$ were determined from the forcedeformation curves.

\section{Microstructural and thermal studies}

In order to monitor the deposition of PLA onto Kraft paper and to follow the presence of different PLA-layers along the cellulose support, Fourier transform infrared spectroscopy in attenuated total reflection mode and MDSC studies were performed as was described previously. Morphology was studied by scanning electron microscope (SEM) with a FEI model Quanta 200 electron microscope (The Netherlands). An uncoated Kraft paper and one Kraft paper coated with a different number of PLA layers were cryogenically frozen in liquid nitrogen. Coated and uncoated Kraft paper with PLA were mounted in block bronze with a double-sided tape, allowing the visualization of both, the surfaces and the cross sections.

\section{Statistical analysis}

Systat-software (SYSTAT, Inc., Evanston, IL, USA) version 10.0 was used for all statistical analysis. Analysis of variance (ANOVA), linear regressions and Fisher LSD mean comparison tests were applied. The significance levels used was 0.05 .

Principal component analysis (PCA) was carried out on mean values by using Infostat v2009 software (Córdoba, Argentina). PCA is a powerful tool capable of reducing the dimensionality of multivariate data while preserving most of the variance, and it is, therefore, an appropriated analysis for revealing relationships among the samples and the variables. This PCA analysis was applied to examine the correlation matrix of the physicochemical and mechanical properties.

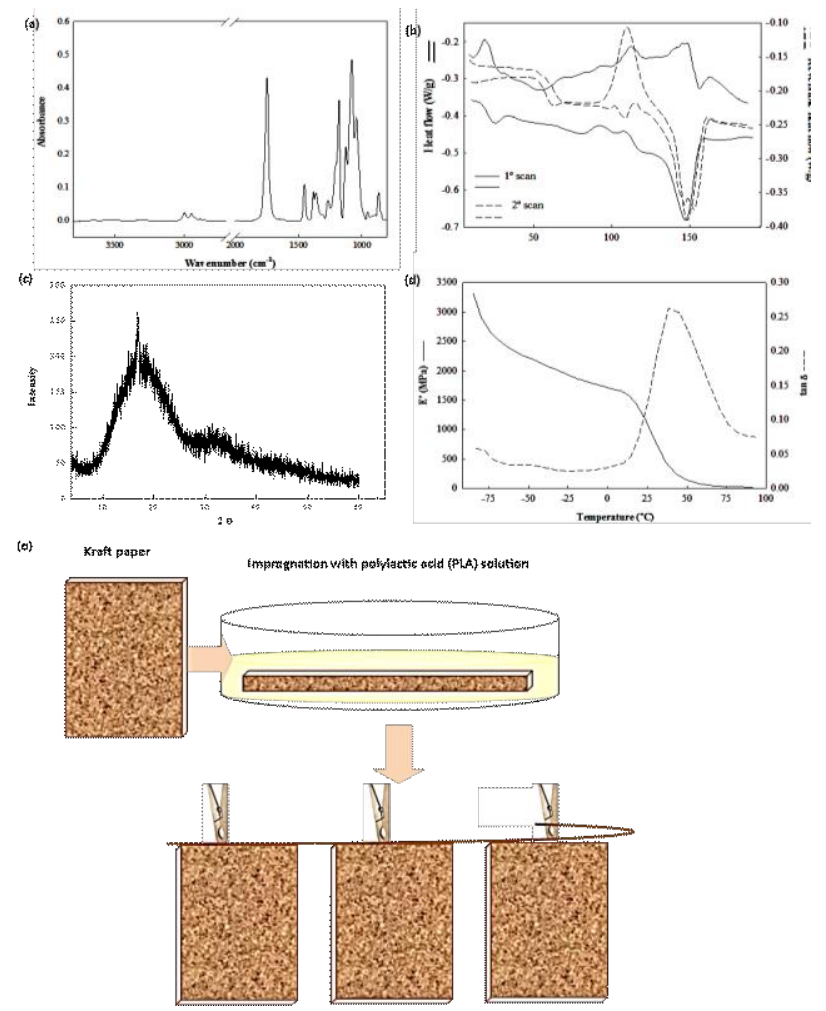

Fig. 1. Spectroscopic and thermal studies of PLA films by mean of: (a) ATR-FTIR, (b) DSC, (c) X-ray and (d) DMA techniques. Representative scheme of the steps involved in the preparation of the PLA coated Kraft Paper (e).

\section{Results and discussion}

\section{Characterization of PLA films}

\section{Spectroscopic and thermal studies}

From FTIR spectra, the functional characteristic groups of the PLA were identified (Fig. 1a), which are consistent with those reported in the literature $[25,26]$. The characteristic peak at around $1755 \mathrm{~cm}^{-1}$ is attributed to the $\mathrm{C}=\mathrm{O}$ stretching vibration from the repeated ester units.

The bands located at $1187 \mathrm{~cm}^{-1}$ and $1095 \mathrm{~cm}^{-1}$ are owing to the asymmetry and symmetry stretching vibration of $\mathrm{C}-\mathrm{O}-\mathrm{C}$. As known, PLA is a hydrophobic polymer due to the presence of $-\mathrm{CH}_{3}$ side groups. The peaks at about $2994 \mathrm{~cm}^{-1}$ and $2944 \mathrm{~cm}^{-1}$ were assigned to the $-\mathrm{CH}$ asymmetric and symmetric stretching vibrations of $-\mathrm{CH}_{3}$ groups in the side chains, respectively, whereas 
the band at $1452 \mathrm{~cm}^{-1}$ was ascribed to the bending vibration of $-\mathrm{CH}$.

The band located at $1745 \mathrm{~cm}^{-1}$ is a strong peak corresponding to the vibration of the carbonyl of the amorphous fraction. Meanwhile, carbonyl vibration of the PLA crystalline fraction at $1755 \mathrm{~cm}^{-1}$ is a very weak signal and cannot be clearly identified in the spectrum.

On the other hand, the thermal properties of PLA films such as the glass transition temperature $\left(\mathrm{T}_{\mathrm{g}}\right)$, the crystallization $\left(T_{c}\right)$ and the melting events $\left(T_{m}\right)$ were investigated by means of modulated differential scanning calorimetry (MDSC) and are shown in Fig. 1b. The recrystallization peak was located in the range $90-135^{\circ} \mathrm{C}$ centered at about $109^{\circ} \mathrm{C}$ with $\Delta \mathrm{H}_{\mathrm{c}}=19.9 \mathrm{~J} \mathrm{~g}^{-1}$ which suggests that some of the amorphous structure in the material underwent a rearrangement to a more structured, crystalline structure. This event was followed by an endothermic transition at $148.1^{\circ} \mathrm{C}$ attributed to the melting of the crystalline phase with an enthalpy associated $\Delta \mathrm{H}_{\mathrm{f}}=21.6 \mathrm{~J} \mathrm{~g}^{-1}$.

After melting, the sample was cooled to a temperature below the glass transition temperature $\left(T_{g}\right)$, and a second scan was recorded. Both, the curves corresponding to total heat flow signal and reversible heat flow showed the $\mathrm{Tg}$ of PLA, which was located at $57.6^{\circ} \mathrm{C}$ (Fig. 1c). This value was comparable to the previously reported values of $57-60^{\circ} \mathrm{C}$ [27].

On the other hand, the XRD spectrum of PLA exhibited a pattern corresponding to an amorphous material with a very low intensity peak at $2 \theta=16.7$ characteristic of the homocrystal form; the degree of crystallinity (CD) estimated was $16.2 \%$. temperature $\left(\mathrm{T}_{\mathrm{g}}\right)$, which was $45.5^{\circ} \mathrm{C}$ at a frequency of $5 \mathrm{~Hz}$.

\section{Application of PLA films}

Kraft paper used in food packaging readily absorbs moisture from the environment, especially when the samples are stored under high humidity conditions, or when experienced contact with water. In this research, the water resistivity was modified by changing the wettability of the support surface, applying layers of hydrophobic coatings of polylactic acid. Thereby, for a potential food application, a multilayer system based on PLA deposited over Kraft paper support was designed. Fig. 1e depicts the diagram of the Kraft paper impregnation procedure. Table 2 shows the variation in average thickness, coating weight, and grammage with successive layers of PLA.

As expected, the coating with PLA solution increased the thickness and the grammage of Kraft paper, this effect being more pronounced with the number of layers. Similar results were reported by Rhim and Kim [17].

Inspecting the PLA coated Kraft paper with the naked eye, the system presented a smooth surface, showing that the higher the number of layers, the higher the glossiness. The first PLA layer was formed without wrinkling or curling of the Kraft paper support after removal of chloroform from the surface of the matrix. This fact could be attributed to the hydrophobic nature of the solvent which had no influence on the hydrophilic cellulose network $[16,17]$.

Further, the PLA layer showed good coverage and excellent adhesiveness to the paper support and no

Table 2. Physicochemical and optical properties of coated and uncoated Kraft paper.

\begin{tabular}{|c|c|c|c|c|c|}
\hline & $\begin{array}{l}\text { Grammage } \\
\qquad\left(\mathrm{g} \mathrm{m}^{-2}\right)\end{array}$ & $\begin{array}{c}\text { Coating weight } \\
\left(\mathrm{g} \mathrm{m}^{-2}\right)\end{array}$ & $\begin{array}{l}\text { Thickness } \\
\qquad(\mu \mathrm{m})\end{array}$ & $\begin{array}{c}\text { Color differences } \\
(\Delta \mathbf{E})\end{array}$ & $\mathbf{L}^{*}$ \\
\hline Kraft paper & $132.04(0.45)^{\mathrm{a}}$ & -- & $149.87(8.34)^{\mathrm{a}}$ & -- & $58.57(0.21)^{d}$ \\
\hline $1 \mathrm{~L}$ & $146.29(3.52)^{b}$ & $16.13^{\mathrm{a}}$ & $167.78(10.01)^{\mathrm{b}}$ & $2.78(0.02)^{\mathrm{a}}$ & $56.19(0.03)^{\mathrm{c}}$ \\
\hline $2 \mathrm{~L}$ & $156.43(3.94)^{b}$ & $24.49^{\mathrm{a}}$ & $185.76(12.77)^{\mathrm{c}}$ & $3.22(0.22)^{\mathrm{b}}$ & $55.81(0.33)^{b c}$ \\
\hline $3 \mathrm{~L}$ & $181.77(10.84)^{\mathrm{c}}$ & $49.74^{b}$ & $196.48(12.01)^{\mathrm{c}}$ & $3.61(0.25)^{\mathrm{c}}$ & $55.61(0.21)^{b}$ \\
\hline $4 \mathrm{~L}$ & $224.16(9.03)^{d}$ & $92.13^{\mathrm{c}}$ & $238.52(20.67)^{d}$ & $4.42(0.09)^{\mathrm{d}}$ & $55.63(0.14)^{b}$ \\
\hline $5 \mathrm{~L}$ & $232.15(7.33)^{\mathrm{d}}$ & $100.11^{\mathrm{c}}$ & $257.24(17.33)^{\mathrm{e}}$ & $4.63(0.22)^{\mathrm{d}}$ & $55.86(0.37)^{\mathrm{bc}}$ \\
\hline 6L & $304.88(7.38)^{\mathrm{e}}$ & $172.85^{\mathrm{d}}$ & $335.37(28.57)^{f}$ & $4.21(0.08)^{\mathrm{e}}$ & $55.74(0.21)^{\mathrm{bc}}$ \\
\hline $7 \mathrm{~L}$ & $330.15(11.83)^{f}$ & $198.11^{\mathrm{e}}$ & $342.27(25.66)^{f}$ & $4.74(0.43)^{\mathrm{e}}$ & $55.06(0.63)^{\mathrm{a}}$ \\
\hline
\end{tabular}

The values in parentheses correspond to the standard deviation. Different letters in the same column indicate significant differences $(p<0.05)$ between samples.

* Coating weights $\left(\mathrm{g} \mathrm{m}^{-2}\right)$ were determined by subtracting the weight of the uncoated Kraft paper from the weight of the coated sample.

Additionally, the thermomechanical properties of the PLA films were studied by DMA. The storage modulus $\left(E^{\prime}\right)$ and $\tan \delta$ curves as a function of the temperature are shown in Fig. 1d.

The storage modulus values had a maximum magnitude of approximately $3.3 \mathrm{GPa}$ at a temperature of $-75^{\circ} \mathrm{C}$. The distinctive peak in $\tan \delta$ curves of the dynamic mechanical spectrum of PLA film corresponded to a relaxation, labeled as dynamic glass transition delamination was observed. These findings were in accordance with those of Rhim and Kim [17], who highlighted the relevance of the PLA affinity for the cellulose fibers to make a well-coated paper support.

Considering film color differences $(\Delta \mathrm{E})$, coated and uncoated Kraft paper may exhibit a brown appearance indicated by a* (not shown) and $\Delta \mathrm{E}$ values. As expected, the lightness (L) of Kraft paper diminished significantly 
$(\mathrm{p}<0.05)$ with the addition of different layers of PLA from 58.6 to 55.0, respectively (Table 2).

\section{Functional properties}

Water vapor transmission rate (WVTR) and water uptake

Fig. 2a shows clearly that the WVTR values decreased significantly $(p<0.05)$ with the addition of PLA in the impregnation of the Kraft paper support. Similar results were reported by Larotonda et al. [13]. It is noteworthy that the WVTR value of PLA film is one order of magnitude lower than that of the Kraft paper. Tsuji et al. [28] reported that the low WVTR values of PLA films are explained in terms of the higher resistance to water permeation.

The addition of 4 layers (4L) allowed to obtain a matrix having a good barrier, similar to PLA films which is probably due to the continuous film formation during the coating process on the support. The ability of the PLA solution to penetrate into the Kraft matrix resulted in a significant reduction by $80 \%$ in WVTR values for Kraft paper coated up to $4 \mathrm{~L}$. No significant differences were observed $(p>0.05)$ in the values of WVTR for Kraft paper support coated with a number of layers higher than 4 . In this sense, Bedane et al. [2] reported that the effective water vapor diffusivity of various paper films decreased with an increase of the density, which implied that WVTR decreased with the increase in film thickness.

Furthermore, a more efficient interfacial barrier was obtained because of the PLA layer adhesion on Kraft paper support. This fact, explains that water movement would be more difficult, decreasing the Kraft paper permeability. Bordenave et al. [9] working on paper coated with chitosan inferred that the preferential ways for water to cross the materials were lengthened and obstructed, which could explain the decrease of moisture transfer. In water diffusion, the microstructure of matrix is involved; the transport proceeds by a solution-diffusion mechanism where crystalline PLA domains increase the tortuosity affecting the diffusion of the penetrants because of they act as a filler [29].

This fact can be explained in terms of the microstructure of the coated Kraft paper and the pores being filled by PLA which reduces the permeation of water vapor molecules through the void spaces between cellulose fibers [30]. This explanation supports the aforementioned reduction in the WVTR values. A similar trend was informed by other packaging papers coated with biopolymers such as WPI [11], SPI soy protein isolate [16], cassava-starch acetate [6, 13], chitosancasein bilayer [10].

The water resistance of the support paper is one of the most important packaging properties. The water uptake provides information on water resistance of the Kraft paper since it indicates how much water the paper can absorb through direct contact [9]. PLA coating reduced drastically the water uptake, which decreased by 18.4 times in comparison to the uncoated samples (Fig. 2b).

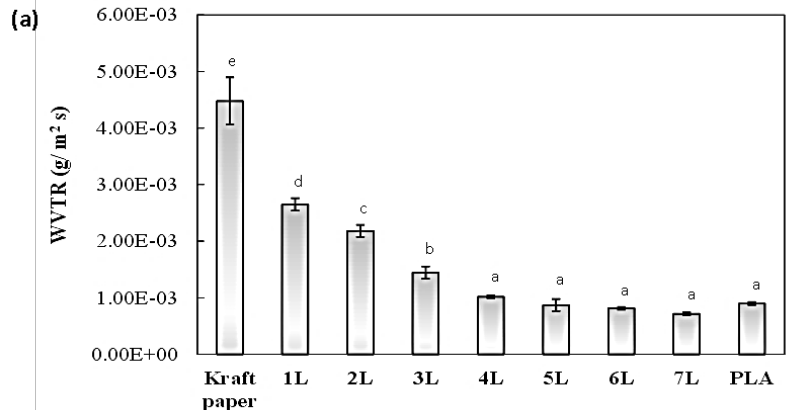

(b)

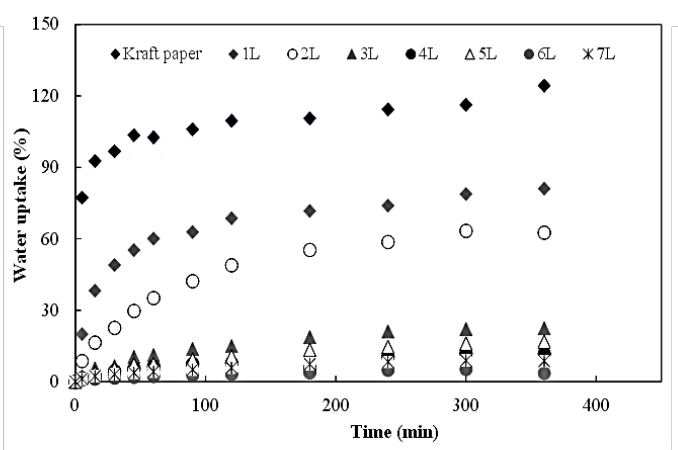

(c)

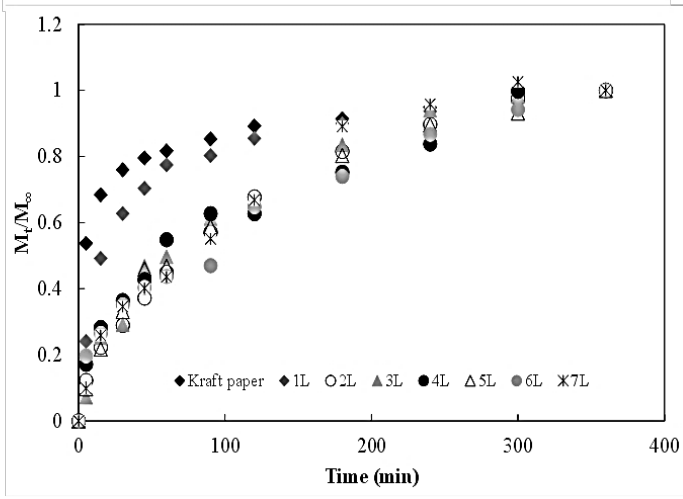

Fig. 2. (a) Water vapor transmission rate (WVTR) of uncoated and coated Kraft paper with different layers of PLA, (b) percentage of water uptake (WA) of uncoated and coated Kraft paper with different layers of PLA; (c) fraction of water uptake $\left(\mathrm{M}_{t} / \mathrm{M}_{\infty}\right)$. The values correspond to the arithmetic average of three measurements.

The water uptake of the coated and uncoated Kraft paper support increased as water contact time increased. The impregnation of the samples with PLA caused some reduction in the water absorption capacity of the matrix, as shown in Fig. 2b whereas uncoated samples absorbed six times more water compared with samples coated with 3 or more PLA layers. The degree of absorption was different depending on the number of coating layers, inferring that the support paper impregnated with more than 3 layers became the system more hydrophobic with the addition of successive coatings up to 7. According to Larotonda et al. [13] the decrease of water absorption of the impregnated papers up to 3 layers suggests that the coating promotes the penetration of the solution into the pores of the paper decreasing its porosity.

Therefore, the coating with PLA solution turned out to be effective in increasing the water resistance of paper support. This trend is in good agreement with Rhim et al. $[16,17]$. In a contrary direction, Han and Krochta [11] reported that the water uptake of paper increased by 
coating with a hydrophilic biopolymer such as whey protein isolate.

Water mass gained was measured as a function of time until an equilibrium state was reached as shown in the Fig. 2c. Transient water adsorption studies were carried out to determine the rate of water uptake and diffusion coefficient through the samples. Mass uptake initially increased rapidly followed by more gradual increase, until a plateau was reached. The Fickian diffusion model was used to determine water diffusion coefficient for different samples [31].

For an infinite plane, the diffusion mechanism in symmetric materials can be expressed in the general form of the microscopic mass balance in terms of an effective matrix diffusivity $\mathrm{D}_{\mathrm{m}}$ :

$$
\frac{d C}{d t}=D_{m} \frac{d^{2} C}{d x^{2}}
$$

where: $\mathrm{C}$ is the concentration in the matrix as a whole expressed as the weight of solute per volume unit; $\mathrm{D}_{\mathrm{m}}$, the effective diffusion coefficient $\left(\mathrm{m}^{2} \mathrm{~s}^{-1}\right)$ and time (s).

The solution for not stationary state has the form of a trigonometric series

$$
\frac{M_{t}}{M_{\infty}}=1-\sum_{n=0}^{\infty} \frac{8}{(2 n+1)^{2} \pi^{2}} e\left[-\frac{(2 n+1)^{2}}{\delta^{2}} \pi^{2} D_{m} t\right]
$$

being, Mœ the asymptotic (equilibrium) water uptake and Mt the water uptake at time $t$.

For the application of the above equations the assumption is that the dimension and physical properties of the material matrices hardly change during the uptake process, i.e. there is no degradation or mass loss of the bulk materials $[32,33]$.

The effective diffusion coefficients were determined from Eq. 4 from uptake rate measurements on the plane sheet of samples by using the computer program Mathcad 7 Professional (MathSoft Engineering and Education, Inc., Cambridge, MA, USA).

The water uptake of the matrix at a given time $\mathrm{Mt}$ and the maximum amount of water that would be incorporated at infinite time $\mathrm{M} \infty$ were used to determine the experimental values of the dimensionless $\mathrm{Mt} / \mathrm{M} \infty$. Values of diffusion coefficients were proposed, and predicted values of $\mathrm{Mt} / \mathrm{M} \infty$ were obtained by means the Eq. 4. In the numerical simulation, the thickness of each sample was considered. The value of diffusivity that led to a minimum sum of the residues and of the square residues was selected by an iterative procedure. Residues were considered as the difference between the experimental and the calculated values of $\mathrm{Mt} / \mathrm{M} \infty$.

The diffusion coefficient (DC) was dependent on the presence or not of PLA layers. In the case of Kraft paper, the diffusion coefficient presented the highest value, which was $1.65 \times 10^{-12} \mathrm{~m}^{2} \mathrm{~s}^{-1}$. With the addition of the first PLA layer, the diffusivity decreased reaching $9.25 \times 10^{-13} \mathrm{~m}^{2} \mathrm{~s}^{-1}$, confirming that the pores filled by PLA reduce the mass transfer through the void spaces. These findings supported the WVTR results. Furthermore, the addition of two layers diminished the DC values to $6.25 \times 10^{-13} \mathrm{~m}^{2} \mathrm{~s}^{-1}$ achieving a plateau for PLA coated Kraft paper with more than $2 \mathrm{~L}$.

\section{Mechanical properties}

During the steps of sealing and/or filling, a package is subjected to thermomechanical stresses that can cause deformities, leading to spoilage. For that reason, during these processes, packages must resist these tensions without losing their structural integrity.

The measure of the ability of PLA coated Kraft paper to resist breaking under tension, which is dependent on the strength of the fibers, the bonding strength/ interaction PLA-support, and the number of PLA layers, is a property to be considered.

Fig. 3a shows an increase in force values $(\mathrm{N})$ after the coating with different layers of PLA respect to uncoated Kraft paper. Analyzing the specimen behavior, the puncture test results suggested that the mechanical properties of the multilayered Kraft paper were superior to those of uncoated samples due to the reinforcing effect. The mechanical profiles of coated Kraft paper showed two different behaviors depending on the number of layers. After the addition of 4 layers of PLA, the appearance of two peaks of rupture was observed. This pattern could be attributed to the rupture of each component of the system, both the PLA coating and the Kraft paper support.

Mechanical profiles of samples impregnated with on less than three PLA layers were controlled by the behavior of cellulose fiber matrix reinforced with the polymer. Regarding the material toughness, the energy required to completely break a specimen was determined, observing a higher area under the mechanical profile with the increase of PLA layers assembled. The coating of Kraft paper with PLA allowed to obtain a tougher material as can be seen in Table inset in Fig. 3a.

Additionally, film heat-sealing capacity was studied. All materials developed capacity of heat-sealing irrespective of the amount impregnated layers. This fact was attributed to the thermoplastic behavior of PLA $\left(\mathrm{T}_{\mathrm{g}}\right.$ and $\mathrm{T}_{\mathrm{m}}$ ), which exhibited, during the seal strength test, a failure mode characterized by a fracture of film at the seal edge (pattern inset in Fig. 3b).

PLA coated Kraft paper supports were able to be heat-sealed obtaining a good quality seal. This could be attributed to the disappearance of the interface between both individual layers, due to their high molecular interaction, allowing to form a new homogenous layer [34]. From the tensile test, two patterns of failure were observed; Kraft paper samples coated up to $4 \mathrm{~L}$ exhibited an adhesive failure, while specimens covered with more layers than 4 presented a delamination failure. For these tests the involved energy to cause adhesive-delamination seal failure increased from 0.02 to $0.15 \mathrm{~J}$ for $1 \mathrm{~L}$ and $7 \mathrm{~L}$ respectively (Table inset in Fig. 3b). On the other hand, tear-propagation resistance was also evaluated for coated and uncoated cellulose support. Tearing resistance is primarily a property of the inner structure of the sheet, but surface treatment could significantly modify its behavior. 
In this sense, the tear-propagation pattern suffered a change at approximately the same amount of layers that those of puncture tests. Concerning the pattern corresponding to PLA matrix, the PLA coated Kraft paper followed a mechanical behavior characteristic and typical of the paper (Fig. 3c).
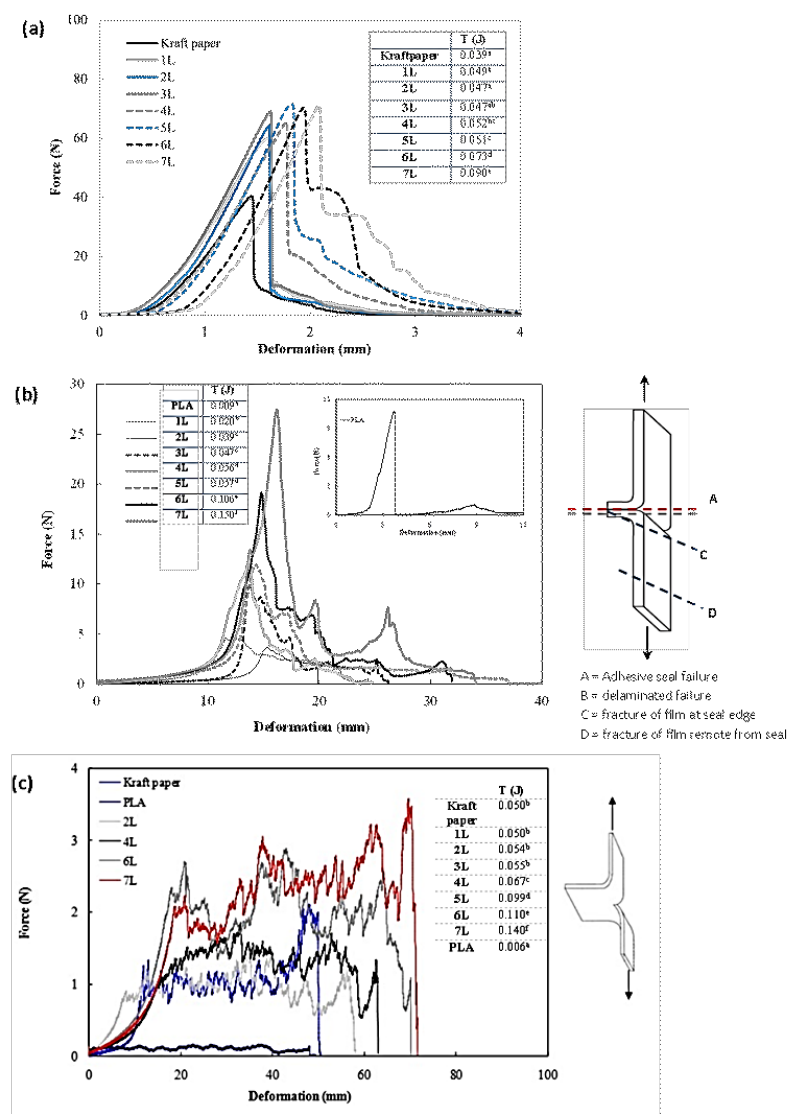

Fig. 3. Mechanical patterns of uncoated and PLA coated Kraft paper: (a) typical curves of puncture resistance; (b) heat-sealing resistance and the associated failure modes; (c) tear-propagation resistance profile. The number of the layers (L) is indicated in the legend. Table inset shows the tenacity $(\mathrm{T})$ values for each assay.

According to ASTM D 1938-02 [24] standard test method, the profiles obtained indicate that Kraft paper, coated and uncoated with PLA, could be associated with low extensible films. Although PLA assembled on Kraft paper did not modify the tear- propagation pattern of the uncoated paper, the multilayered materials presented higher average tear-propagation force and higher values of deformation. A similar trend was explained by Sharif et al. [35] working on sheets made of an assembly of cassava leaves and polylactic acid films. The authors reported that PLA concentrations from 4 to $8 \%$ lead to higher tear index, due to the polymer forms a continuous layer on the substrate reinforcing the matrix. In the same way, Thellen et al. [36] obtained comparable tear resistance values for the co-extrusion of multilayer poly(m-xylylene adipimide) nanocomposite films.

\section{PCA analysis}

The PCA analysis involves a calculation of a covariance matrix of a data set to minimize redundancy and maximize variance [37]. In a bi-plot, the length of the lines approximates the variances of the variables. Lines are used to reflect the variables of the dataset (grammage $\mathrm{G}$, coating weight $\mathrm{CW}$, thickness $\mathrm{T}$, water uptake WA, WVTR, a*, L*, puncture area, puncture Fmax, heatsealing area, heat-sealing Fmax, tear-propagation area, tear propagation Fmax) and dots are used to show the observations (Kraft Paper, 1, 2, 3, 4, 5, 6, and 7L). The obtained results are displayed as a two-dimensional graph of the first two PCs (PC1 and PC2). These plots either reveal similarities or differences among the samples or represent relationships among the variables. It is worth bearing in mind that the relative proximity of variables indicates a degree of their linear correlation. Additionally, PCA bi-plot shows the similarities and dissimilarities among the samples [38].

PCA bi-plot shows the relationships between Kraft paper samples impregnated with different layers of PLA, and physicochemical, optical, and mechanical properties (Fig. 4a). PCA allows to simplify the analysis of several samples and variables by combining them. The variables were reduced to two components. Inspecting these contributions, the variability explained by the first component was $81.5 \%$ (PC1) and the second one $12.3 \%$ (PC2), the total variation in all data being 93.8\%. The score plot shows that samples coated with less than $4 \mathrm{~L}$ can be found on the left side of the diagram, whereas those coated with higher than $4 \mathrm{~L}$ are located on the left side.

The uncoated Kraft paper was better interpreted in terms of water uptake (WA) and WVTR whereas samples impregnated with more than five layers $(5 \mathrm{~L})$ were located opposite to these properties. These samples were more associated with the coating weight $(\mathrm{CW})$, thickness $(\mathrm{T})$, grammage $(\mathrm{G})$, puncture area, puncture $F_{\max }$, heat-sealing area, heat-sealing $F_{\max }$, tear-propagation area, tear propagation $\mathrm{F}_{\max }$.

The bi-plot depicts the clustering of coated samples in three groups: 1, 2 and 3L, 3, 4 and 5L, and 5, 6 and 7L. Coated samples 4 and $5 \mathrm{~L}$ were located in the center of the graph approximately equidistant from all studied variables.

The uncoated Kraft paper was separated from samples impregnated with different PLA layers and the separation was realized along PC1.

The angle between the lines approximates the correlation between the variables they represent. Grammage, thickness, coating weight, puncture area, tearpropagation area, tear-propagation $\mathrm{F}_{\max }$, heat-sealing area, heat sealing $\mathrm{F}_{\max }$ reflected correlations closer to 1 , since their lines form angles near 0 degrees. Meanwhile, these variables are positioned at approximately right angles to L*, WVTR, WA, showing a weak correlation among them.

\section{Microstructural and thermal analysis}

ATR-FTIR analyses were performed on both sides of uncoated and coated Kraft paper to detect the impregnation process of Kraft paper matrix. The formation of the adhesive bonds in the interface region 
between the Kraft paper substrate and the polymer PLA could have an important role in the enhancement of the packaging based paper properties.
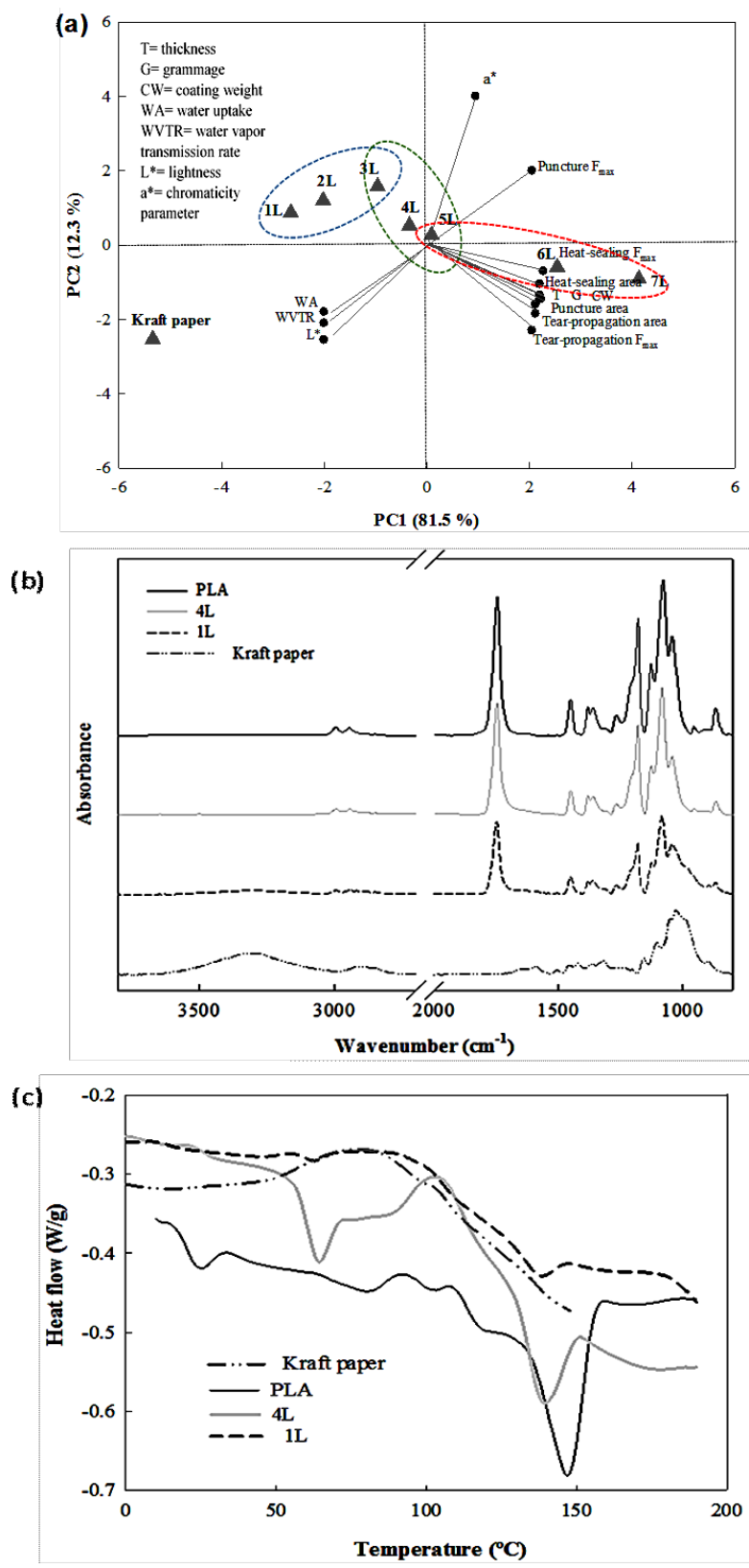

Fig. 4. (a) PCA biplots summarize the relationships between Kraft paper samples impregnated with different layers of PLA, and physicochemical, optical, and mechanical properties. Spectroscopic and thermal studies of Kraft paper coated with different layers of PLA by means of: (b) ATRFTIR, (c) DSC.

Characteristic bands of PLA were previously described. As can be observed in Fig. 4b depicting coated Kraft paper, the band at $3300 \mathrm{~cm}^{-1}$ became weaker with the addition of successive PLA layers. The most plausible explanation is that the PLA interacts favorably with the substrate reducing the environmental moisture uptake of the cellulose matrix, thus increasing the hydrophobic character of the PLA coated Kraft paper and restricting the water molecules.
The apparition of carbonyl peak ester at $1745 \mathrm{~cm}^{-1}$ was an evidence of the PLA presence in samples of coated Kraft paper, rising with the PLA successive layers.

Additionally, the interactions Kraft paper-PLA coating was confirmed by DSC technique. As can be seen in Fig. 4c the addition of 1L evidenced the apparition of a thermal event due to the melting of the PLA in close contact with the paper at lower temperatures in relation to PLA film. This fact could be attributed to the interaction between the cellulose support and the polymer. At this point, it would be worth bearing in mind that the cellulose matrix restricts the PLA chains organization into crystalline lamella modifying the thermal profile.

The micrographs of PLA matrix revealed a compact and homogeneous structure (Fig. 5a). Fig. 5b and c shows the cross-sections examined by SEM of samples of Kraft paper coated with a different number of PLA layers. Micrographs indicate that the porosity and fibrous network characteristic of the Kraft paper was covered and filled with PLA layers. These results suggested that PLA behaves as a pore-filler of the cellulose matrix. According to Rhim et al. [16], the coating with PLA acts in a similar way to fillers, similar to clay. Fillers are deposited in the void areas on the surface of the paper to provide a smoother structure and a lower surface roughness.

The PLA coated Kraft paper showed good appearance, flexibility and adhesion between the coating and the cellulosic support. As it can be seen in the micrographs, there is no clear interface between the Kraft paper and the first PLA layer, as well as among the subsequent PLA layers. At this point, it would be worth bearing in mind that the number of layers employed in the impregnation process was not distinguished, forming a continuous matrix on the substrate. This fact would indicate the stickiness level of the coating to the substrate.

The first phenomenon could be a consequence of the penetration and filling of the paper pores owing to the interaction of PLA with the hydrophilic fibers [17]. This coupled with the lower hygroscopicity of the material by the addition of PLA, which explains the better barrier properties due to a lower water vapor transmission through the films in relation to the uncoated Kraft paper.

Moreover, the cross section of the film shows the internal porosity of the material and the impregnation predominantly near the material surface, showing changes in the cellulose fiber network. These results could explain the changes in mechanical properties of the multilayer systems.

As layer increased, uniformity and smoothness of the coating on the support also increased. Similar results were reported by Taboada-Rodríguez et al. [39]. In this sense, surface roughness has an important influence on the printing quality given that it also affects properties such as the coefficient of friction, gloss, and coating absorption. According to Izdebska and Thomas [40], the main factors which influence the printing performance are substrate properties, determined by its porosity, thickness, smoothness, surface cohesion, and mechanical properties. All samples presented print capacity, increasing their 
printing quality with the increase in the number of layers. Fig. 5d shows the effect of surface coating on visual print quality.

(a)

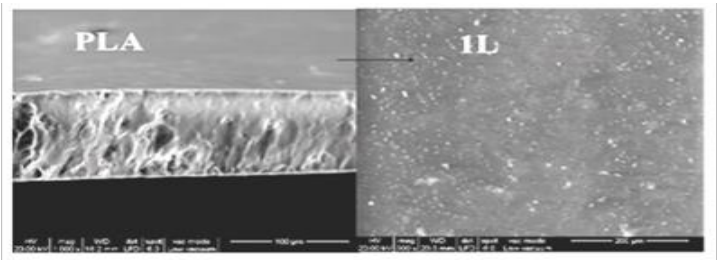

(b)

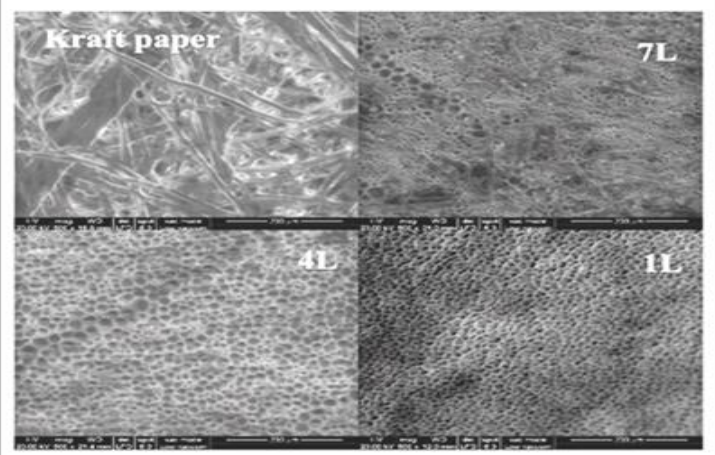

(c)

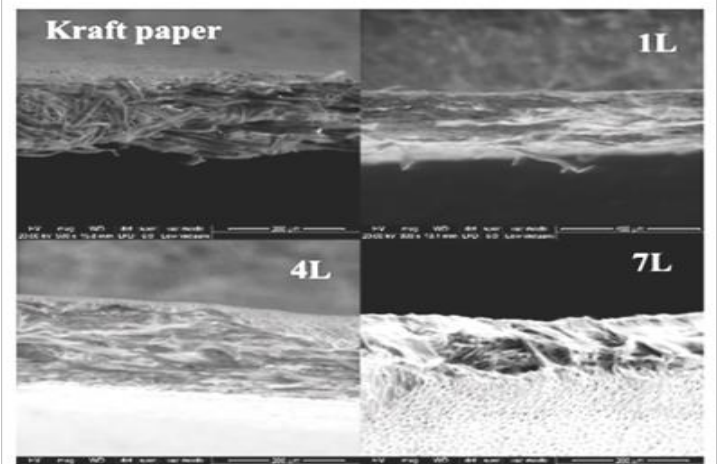

(d)
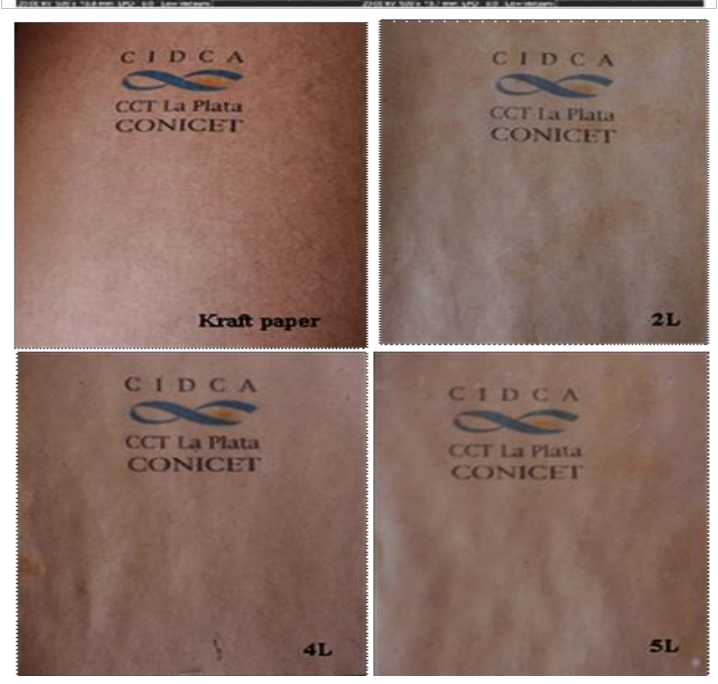

Fig. 5. SEM micrographs of: (a) surface morphology and cross-section of PLA films; (b) surface of Kraft paper and samples coated with 1, 4, 7 layers; (c) cross-section of Kraft paper and samples coated with 1, 4, 7 layers (L). (d) Photographs showing the impression capacity of uncoated and PLA coated Kraft paper with 2, 4, and 5 layers (L).

\section{Conclusion}

PLA coated Kraft papers are very promising systems for future developments in the food packaging. This ecofriendly biopolymer has potential environmental advantages over conventional synthetic paper coatings. The results obtained showed that the coating with PLA solution improved packaging material performance and hence the functional properties of Kraft paper. The impregnation of hygroscopic materials as the Kraft paper with PLA solution enabled more hydrophobic matrices and was an interesting alternative to enhance the properties related to the water affinity. The assembled materials obtained were heat-sealable and improved the barrier and mechanical properties and the printing quality. Thereby, control of paper surface properties by coating is important for tuning water resistance, mechanical performance and printing properties when these materials are used as a packaging material. The design of this multilayer support allows its extension to other media such as paperboard. Moreover, the addition of 4 or 5 layers favorably modified the assembled system properties. Increasing even further the number of PLA layers, system properties hardly underwent a significant improvement. Consequently, the selection of the number of PLA layers would be a response to a relationship of commitment between the increase in the cost and the enhancement of the properties.

\section{Acknowledgements}

This work was supported by the Argentinean Agency for the Scientific and Technological Promotion (ANPCyT) (Project PICT 2012-0415 and Project PICT 2014-1620) and the Argentinean National Research Council (CONICET) (PIP 20130109). Authors acknowledge Mr. Daniel Russo for technical assistance.

\section{References}

1. Khwaldia, K.; Arab-Tehrany, E.; Desobry, S. Compr.; Rev. Food Sci. Food Saf., 2010, 9(1), 82.

DOI: $10.1111 / \mathrm{j} .1541-4337.2009 .00095 . \mathrm{x}$

2. Bedane, A.H.; Huang, Q.; Xiao, H.; Ei, M. Nord. Pulp Pap. Res. J., 2012, 27(2), 409.

DOI: 10.3183 /NPPRJ-2012-27-02-p409-417

3. Armentano, I.; Fortunati, E.; Burgos, N.; Dominici, F.; Luzi, F.; Fiori, S.; Jiménez, A.; Yoon, K.; Ahn, J.; Kang, S.; Kenny, J.M.; Express Polym. Lett., 2015, 9, 583.

DOI: $10.3144 /$ expresspolymlett.2015.55

4. Gupta, B.; Revagade, N.; Hilborn, Prog. Polym. Sci., 2007, 32(4), 455.

DOI: 10.1016/j.progpolymsci.2007.01.005

5. Archaviboonyobul, T.; Jinkarn, T.; Sane, S.; Chariyachotilert, S.; Kongcharoenkiat, S., Packag. Technol. Sci., 2014, $27(5), 341$.

DOI: $10.1002 /$ pts.2034

6. Larotonda, F.D.S.; Matsui, K.N.; Sobral, P.J.A.; Laurindo, J.B.; J. Food Eng., 2005, 71(4), 394.

DOI: $10.1016 /$ j.jfoodeng.2004.11.002

7. Rivero, S.; Garcia, M. A.; Pinotti, A.; J. Food Eng., 2009, 90, 531. DOI: $10.1016 / \mathrm{j} . j$ foodeng.2008.07.021

8. Gu, C-H.; Wang, J-J.; Yu, Y.; Sun, H.; Shuai, N., Wei, B.; Carbohyd. Polym., 2013, 92, 1579.

DOI: $10.1016 /$ j.carbpol.2012.11.004

9. Bordenave, N.; Grelier, S.; Pichavant, F.; Coma, V.J.; Agric. Food Chem., 2007, 55(23), 9479.

DOI: $10.1021 / \mathrm{jf070595i}$

10. Khwaldia, K.; Basta, A.H.; Aloui, H.; El-Saied, H.; Carbohydrate Polym., 2014, 99(0), 508.

DOI: $10.1016 / \mathrm{j} . \mathrm{carbpol} .2013 .08 .086$

11. Han, J.H.; Krochta, J.M.; J. Food Sci., 2001, 66(2), 294. DOI: $10.1111 / \mathrm{j} .1365-2621.2001 . \mathrm{tb} 11335 . \mathrm{x}$

12. Matsui, K.N.; Larotonda, F.D.S.; Paes, S.S.; Luiz, D.D.B.; Pires, A.T.N.; Laurindo, J.B.; Carbohydrate Polym., 2004, 55(3), 237. DOI: $\underline{10.1016 / \text { j.carbpol.2003.07.007 }}$ 
13. Larotonda, F.D.; Matsui, K.S.; Paes, S.S.; Laurindo, J.B.; StarchStärke, 2003, 55(11), 504. DOI: $10.4260 /$ BJFT2009260700005

14. Shawaphun, S.; Manangan, T.; Science Journal Ubon Ratchathani University, 2010, 1(1), 51-57.

15. Rhim, J.-W.; Lee, J.-H.; Hong, S.-I.; LWT - Food Sci. Technol., 2006, 39(7), 806.

DOI: $\underline{10.1016 / \text { j.lwt.2005.05.008 }}$

16. Rhim, J.-W.; Lee, J.-H.; Hong, S.-I.; Packag. Technol. Sci., 2007, 20(6), 393.

DOI: $10.1002 / \mathrm{pts} .767$

17. Rhim, J.-W.; Kim, J.-H.; J. Food Sci., 2009, 74(2), E105.

DOI: $10.1111 / \mathrm{j} .1750-3841.2009 .01073 . \mathrm{x}$

18. Rivero, S.; Garcia, M. A.; Pinotti, A.; Adv. Mat. Lett., 2014, 5(10), 578. DOI: $10.5185 /$ amlett.2014.5582

19. Villarruel, S.; Giannuzzi, L.; Rivero, S.; Pinotti, A.; Mat. Sci. Eng. C., 2015, 56, 545 .

DOI: $10.1016 / \mathrm{j} . \mathrm{msec} .2015 .07 .003$

20. ASTM (1995). Standard test methods for water vapor transmission of material, E96-95. Annual book of ASTM Philadelphia, PA: American Society for Testing and Materials.

21. Siracusa, V.; Blanco, I.; Romani, S.; Tylewicz, U.; Rocculi, P.; Rosa, M.D.; J. Applied Polym. Sci., 2012, 125(S2).

DOI: $10.1002 /$ app.36829

22. American Society for Testing and Materials - ASTM, 2001a. Standard Test Method for Seal Strength of Flexible Barrier Materials - ASTM F88-00, vol. 15.09. ASTM Standards on Disc. ASTM, Philadelphia, p.6.

23. López, O.V.; Lecot, C.J.; Zaritzky, N.E.; García, M.A.; J. Food Eng., 2011, 105(2), 254.

DOI: $\underline{10.1016 / \text { j.j.joodeng.2011.02.029 }}$

24. ASTM (2002). Standard test methods for tear-propagation resistance (Trouser Tear) of plastic film and thin sheeting by a single-tear method. D1938-02. Annual book of ASTM Philadelphia, PA: American Society for Testing and Materials.

25. Meng, Q.; Hu, J.; Ho, K.; Ji, F.; Chen, S.; J. Polym. Environ., 2009, 17(3), 212.

DOI: $10.1007 / \mathrm{s} 10924-009-0141-\mathrm{z}$

26. Ashok, B.; Naresh, S.; Reddy, K.O.; Madhukar, K.; Cai, J.; Zhang, L.; Rajulu, A.V.; Int. J. Polym. Analysis and Charact., 2014, 19(3), 245.

DOI: $10.1080 / 1023666 X .2014 .879633$

27. Tabi, T.; Sajó, I.; Szabo, F.; Luyt, A.; Kovács, J.; Express Polym. Lett., 2010, 4(10), 659.

DOI: 10.3144 /expresspolymlett.2010.80

28. Tsuji, H.; Okino, R.; Daimon, H.; Fujie, K.; J. Appl. Polym. Sci. 2006, 99, 2245.

DOI: $\underline{10.1002 / a p p .22698}$

29. Aldana, D.S.; Villa, E.D.; De Dios Hernández, M.; Sánchez, G.G.; Cruz, Q.R.; Gallardo, S. F.; Castillo, H.P.; Casarrubias, L.B.; Polymers, 2014, 6(9), 2386.

DOI: $\underline{10.3390 / \text { polym6092386 }}$

30. Reis, A.B.; Yoshida, C.M.; Reis, A.P.C.; Franco, T.T.; Polym. Int., 2011, 60(6), 963.

DOI: $10.1002 /$ pi.3023

31. Crank J.; The Mathematics of Diffusion, Oxford University Press. Second Edition, London, 1975.

DOI: 0198534116

32. Fu, Y.; Kao, W.J.; Expert Opin. Drug Deliv., 2010, 7(4), 429.

DOI: $10.1517 / 17425241003602259$

33. Kurek, M.; Guinault, A.; Voilley, A.; Galić, K.; Debeaufort, F.; Food Chem. 2014, 144, 9.

DOI: $10.1016 /$ j.foodchem.2012.11.132

34. Cho, S.-W.; Ullsten, H.; Gällstedt, M.; Hedenqvist, M.S.; J. Biobased Mater. Bio., 2007, 1(1), 56.

DOI: $10.1166 / \mathrm{jbmb} .2007 .006$

35. Sharif, N.F.A.; Razak, S.I.A.; Nayan, N.H.M.; Yahya, M.Y.; Rahman, W.A.W.A.;. Cell. Chem. Technol., 2015, 49(7-8), 659.

36. Thellen, C.; Schirmer, S.; Ratto, J.A.; Finnigan, B.; Schmidt, D.; J. Membrane Sci., 2009, 340,45.

DOI: $\underline{10.1016 / \text { j.memsci.2009.05.011 }}$

37. Anker, M.; Stading, M.; Hermansson, A.M.; J. Agric. Food Chem., 1998, 46(5), 1820. DOI: $\underline{10.1021 / \text { jf } 9708711}$
38. Letnar, M.Č.; Hladnik, A.; Kropar-Vančina; V. Acta Graphica, 2003, $15,13$.

DOI: $1848-3828$

39. Taboada-Rodríguez, A.; García-García, I.; Cava-Roda, R.; LópezGómez, A.; Marín-Iniesta, F.; J. Coatings Tech. Res., 2013, 10(5), 749-755.

DOI: $10.1007 / \mathrm{s} 11998-013-9493-3$

40. Izdebska, J.; Thomas, S. Printing on Polymers: Fundamentals and Applications. William Andrew, 2015.

DOI: 9780323374682

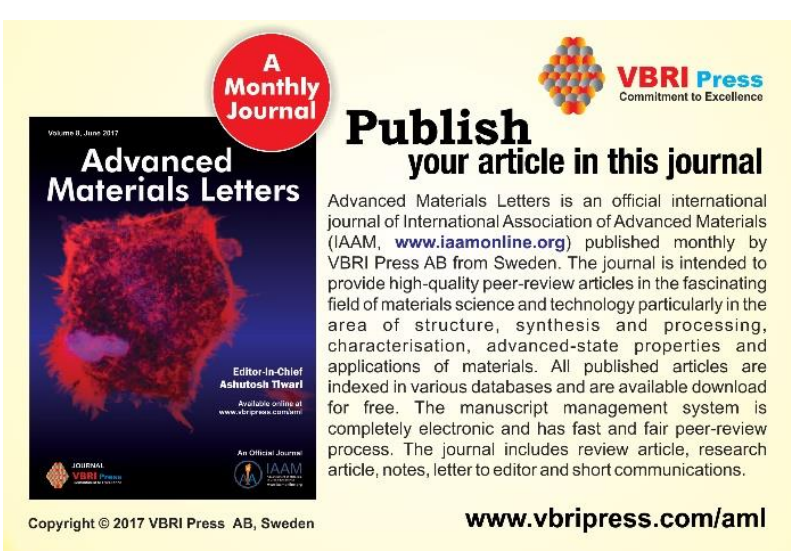

